\title{
How Preservice Content Teacher Background Qualities Influence Their Attitude and Commitment to Supporting Multilingual Learners
}

\author{
Adam V. Agostinelli*1 \& Patrick McQuillan ${ }^{1}$
}

* Corresponding author

E-mail: agostiad@bc.edu

1. Boston College, Boston, MA, USA

\section{Article Info}

Received: June 5, 2020

Revised: September 7,2020

Accepted: September 25,2020

\section{$10.46303 / j \operatorname{csr} .2020 .12$}

This is an Open Access article distributed under the terms of the CC BY 4.0 International license. (https://creativecommons.org/licenses/by/4.0/)

\section{How to cite}

Agostinelli, A. \& McQuillan, P. (2020). How Preservice Content Teacher Background Qualities Influence Their Attitude and Commitment to Supporting Multilingual Learners. Journal of Curriculum Studies Research, 2(2), 98-121. https://doi.org/10.46303/jcsr.2020.12

\begin{abstract}
With the growing number of multilingual learners (MLs) in U.S. schools, research relating to effective teacher training methods has gathered increased interest; however, research on how teachers' background qualities (BQs) influence teaching practices for MLs is lacking. In the field of multilingual education, scholars have suggested that certain qualities, particularly cultural and linguistic backgrounds, contribute to effectively accounting for MLs in the content classroom and embracing the role of language teacher. In this study we draw upon in-class comments, classroom interactions, targeted interviews, and assignments from teachers-in-training $(\mathrm{N}=12)$ throughout one semester in a history teaching methods course to address the following research question: How do prospective teachers' language-related BQs (i.e. MLrelated education, cultural experiences, language learning experience, and teaching experience) shape how they approach ML-related activities and assignments in a content methods teacher education course? The data indicate that preservice teachers with these BQs were better prepared to embrace their roles as language teachers and tailor lessons for MLs than their peers without such BQs.

KEYWORDS

Teacher Education; Multilingual Learners; Preservice Teachers; Background Qualities; History Methods.
\end{abstract}




\section{INTRODUCTION}

With the growing number of multilingual learners (MLs) ${ }^{1}$ in U.S. schools, research relating to effective teacher education methods for working with this population has gathered increased interest (Brisk et al., 2014; DiCerbo et al., 2014; Viesca \& Teemant, 2019); however, as Viesca \& Teemant (2019) observe, "the existing conceptual and empirical knowledge-base for preparing pre- and in-service content teachers is still in its infancy." (p. 371). Specifically, in the field of bilingual education scholars have suggested that certain background features, particularly the cultural and linguistic, contribute to teachers effectively accounting for MLs in the content classroom (Clayton, 2013; Jimenez \& Rose, 2011; Lucas \& Grinberg, 2008) and embracing the role of language teacher (Schall-Leckrone \& McQuillan, 2012). Seeking to enrich our understanding of background and contextual factors that shape the ability and inclination of pre-service teachers to work effectively with MLs, we undertook a semester-long study of a secondary history methods course we taught in Fall, 2019. Drawing upon pre- and post-course surveys, in-class observations, targeted interviews, and assignments from our pre-service teachers $(\mathrm{N}=12)$ we address the following research question:

- How do prospective teachers' language-related background qualities (i.e. education, cultural experiences, language learning experience, and teaching experience) shape how they approach ML-related activities and assignments in a content methods teacher education course?

\section{Literature Review}

Although a growing field, multiple researchers have called for further research on how to prepare preservice content teachers to work with MLs (Clark \& Medina, 2000; Jimenez \& Rose, 2010; Lucas \& Grinberg, 2008; Marquez-Lopez, 2005; Sleeter, 2008). Several have explored strategies to help content teachers work with MLs (Anstrom, et al. 2010; Brisk, et al. 2014; Viesca \& Teemant, 2019), often focusing on those qualities which are markers of effective teachers of MLs (Clayton 2013; Lucas \& Grinberg 2008) and proposing that certain background qualities (BQs) intertwine with their ability and inclination to accommodate MLs.

In a literature review, Anstrom and her colleagues (2010) outlined the academic English demands of each subject area, detailing, for instance, how those in history classrooms are unique because of the background context necessary to engage the material as well as the text structures and syntactic features unique to this discipline, all of which complicate challenges faced by MLs (Short 1994). In a related vein, Zwiers (2006) found that MLs are more inclined to use academic English and engage in critical thinking when the instructor articulates their thought processes and academic English is "modeled, scaffolded, and practiced in the ways that

\footnotetext{
${ }^{1}$ Terms referencing those learning second, third and more languages seem to constantly evolve. We think it is respectful and empowering to describe such persons as "multilingual learners," so we therefore use this terminology, to highlight the possibility that they may be learning more than one language, and abbreviate references to this population as "MLs." When authors we cite use alternative terms, such as "ELLs," we include their specific terminology.
} 
historians think about history" (p. 330). Thus, academic English needs to be taught in tandem with discipline-specific content and analytic skills.

Jimenez \& Rose (2010) identified an additional factor intertwined with teaching MLs: preservice teachers who have lived abroad or have in-depth language learning experience seem better prepared to meet the needs of MLs, suggesting that preservice teachers lacking such experience engage in field-based research with $M L$ populations (i.e. visiting neighborhoods and collecting materials in different languages) to generate empathy and understanding. Additionally, they suggest three strategies content teachers can employ to support MLs: identifying language objectives (LOs), providing accessible content, and connecting lessons to students' backgrounds.

Moreover, in a foundational review, Lucas \& Grinberg (2008) specifically focused on preservice and in-service teacher preparation, dedicating considerable attention to teacher background and identity, traits they see as markers of effective teachers of MLs. They propose four overarching categories concerning "language-related qualities teachers need for teaching ELLs" (p. 61): (1) attitudes and beliefs about teaching ELLs; (2) knowledge for teaching ELLs; (3) skills for teaching ELLs; and (4) experiences of teaching ELLs. In this final category, they highlight that studying a second language and having contact with speakers of languages other than English can enrich teachers' ability and inclination to teach ELLs. This final dimension is central to our study, as it directly connects content teachers' previous experiences and their ability to accommodate MLs with their teaching.

Furthermore, in a study of ESL instructors Clayton (2013) argued that certain background characteristics were predictors of exemplary teachers of MLs-including previous ML teaching, second language learning, and cultural immersion experiences. Master et al.'s (2016) research provides further evidence that experiences with MLs and ML-related professional learning opportunities can shift attitudes towards teaching this population. As the authors note, “...prior teaching experience teaching ELLs predicts improvements in novice teacher's differential instructional effectiveness with ELLs" (p. 1).

Offering something of a shift in focus, De Jong \& Harper (2008) emphasize that "standard curriculum teachers need to embrace the role of language teacher" (p. 137), which in practice requires understanding the linguistic demands of their content area (Brisk et al., 2014). However, this often proves challenging since most teacher candidates are monolingual English speakers lacking meaningful second language learning experience and having limited interactions with multilingual learners (Brisk et al., 2014). Multiple studies have also identified the value of having content teachers embrace a commitment to working with language specialists as a marker of an effective teacher of MLs (Hopkins et al., 2019; Lucas \& Grinberg, 2008; Martin-Beltran \& Peercy, 2014; Schall-Leckrone \& McQuillan, 2013; Viesca \& Teemant, 2019).

Finally, Schall-Leckrone \& McQuillan conducted two previous ML-related studies (2012 and 2013) in the same history methods course observed in this study. In both studies a team of 
language learning experts infused three modules linked to enriching students' ability to craft LOs and related strategies for history lessons into the methods course. In both courses, researchers utilized Systematic Functional Linguistics (SFL) to "do history" and prepare preservice history teachers to account for MLs. In this context, "[d]oing history connotes processes historians use to construct knowledge, including sourcing, contextualizing, and corroborating" (Hynd, et al. 2004 via Schall-Leckrone \& McQuillan, 2012 p. 247), and SFL addresses the authentic use of language for a specific purpose and audience (Fang \& Schleppegrell, 2008). We see these strategies as similar-attending to matters of context, audience, and language choice-and therefore appropriate for use with MLs.

Results were mixed in both studies. Some students embraced the role of language teacher and the importance of incorporating academic LOs into their lessons, while others seemed confused and frustrated when challenged to embrace this role and integrate what some perceived as an irrelevant, extra burden. In the words of one participant: "Honestly, this all means nothing to me until I get into the classroom... I just want to teach" (Schall-Leckrone \& McQuillan, 2012, p. 256). Similarly, a general trend revealed that some students felt prepared to teach MLs, but a contrary trend emerged in students' inability to create robust LOs and integrate SFL analysis into their teaching. As one student noted: "[I]n general, we struggle with ... language objectives. A lot of us don't understand the point of them . . . . it's not something that comes natural to me" (Schall-Leckrone \& McQuillan, 2013, p. 93).

In response to these trends, Schall-Leckrone \& McQuillan (2013) called for greater coherence in teacher training programs in terms of closer collaboration between content instructors and language specialists. They also wondered whether expecting novice content teachers to fully embrace the role of language teacher and create effective LOs for MLs was overwhelming:

Perhaps a more reasonable outcome of infusing ELL strategies into a content methods course would be to encourage novice teachers to recognize the complexity of historical language, appreciate their role as language teachers, and develop a repertoire of strategies to scaffold academic language instruction in history classes. (Schall-Leckrone \& McQuillan, 2013, p. 96)

These two studies serve as valuable reference points for understanding our research. Incorporating ML-related modules into the history methods course began in 2011, and despite the efforts and collaboration of the instructor of the history methods course and language learning experts and professionals at Boston College some students still struggled to embrace the role of language teacher nearly 10 years later in our course. We hope that our study supplements this research, as we account for an important variable omitted from these studies: teacher background. Perhaps this is the missing piece of the puzzle? Could it be that students struggled with the role of language teacher due to a lack of previous language-related background experiences? To address this question, we draw upon established predictors of being a good ML teacher as noted in our Literature Review (Clayton, 2013; Lucas \& Grinberg, 
2008) and consider how language-related background qualities influenced whether and how preservice history teachers embraced, or distanced, themselves from the role of language teacher.

\section{METHODOLOGY}

\section{Conceptual Framework}

As noted, we view our participants' multiple standpoints, roles, and realities through the lens of their background qualities (see Figure 1 below), an encompassing construct we generated from our reading of the extant literature on connections between preservice teachers' background qualities and the impact of these qualities on their inclination and ability to embrace practices and ideals linked to teaching MLs.

Figure 1: Background Qualities, as adapted from Lucas \& Grinberg (2008)

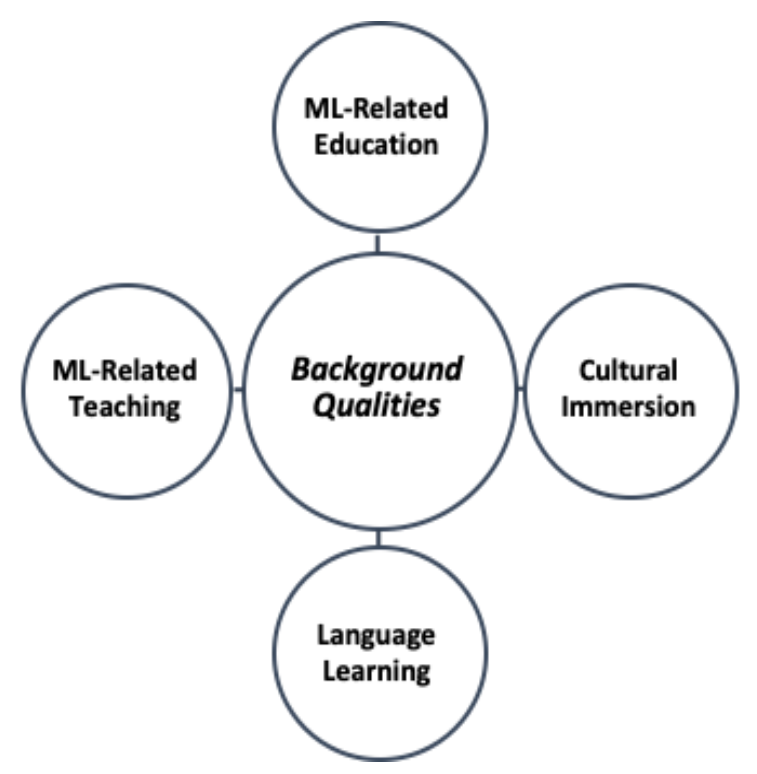

To be effective instructors of MLs, Lucas \& Grinberg (2008) maintain that teachers need certain language-related background features-which they delineate as experiences, attitudes and beliefs, knowledge, and skills-maintaining that these qualities are often overlooked during teacher education courses. While their constructs serve as a holistic list of language-related qualities necessary to instruct MLs, we focus specifically on how pre-existing language-related qualities of pre-service teachers affect their ability to account for MLs during a history methods course. As such, two constructs outlined by Lucas and Grinberg (2008), namely the study of a second language and contact with people who speak languages other than English, directly relate to our conception of pre-existing language-related qualities we term ML-related background qualities (BQs). Additionally, in her study of exemplary teachers of MLs, Clayton (2013) found that a teacher's background experiences, particularly second language learning 
experiences, being immersed in a culture other than their own, and the amount of time spent teaching MLs, influenced their ability to successfully teach MLs. Finally, in response to CochranSmith \& Fries' (2005) call for more research that connects the "baseline knowledge and understandings" that novice teachers bring with them to teacher education courses and what they actually learn, we attempt to make such a connection by observing preservice teachers' inclass performance in light of these ML-related BQs.

Adopting the aforementioned qualities from Lucas \& Grinberg (2008) and Clayton (2013) we propose the following four categories of relevant BQs: ML-related education, cultural immersion, language learning, and ML-related teaching experience. Each construct represents different previous experiences and knowledge students bring into teacher education courses, and we believe all are intertwined with student engagement and ability to enact ML-related coursework.

ML-related education. Lucas \& Grinberg (2008), amongst others (Brisk, 2015; De Jong and Harper, 2005; Viesca \& Teemant, 2019), believe content teachers can become effective educators of MLs with appropriate learning opportunities. Accordingly, we suspect that students in content area courses who already completed formal ML-related coursework are more likely to embrace and effectively enact the role of language teacher than classmates lacking such experience, which often occurs because schools of education structure students' programs of study so that some enroll in content electives before taking ML-related coursework, thus they have no foundation to build upon.

Cultural immersion. Clayton's (2013) findings suggest that having cultural immersion experiences can prepare novice educators to become successful teachers of MLs. While her study included exemplary teachers who were immersed in foreign nations, we embrace Lucas \& Grinberg's (2008) more holistic notion of "cultural experience" to include students having significant interaction with speakers of languages other than English, as their findings suggest that increased contact with MLs promotes a more positive disposition toward them. This construct, therefore, could be the result of extended periods abroad and encompasses previous contact with ML friends, family members, neighbors, classmates, coworkers, or acquaintances (Youngs \& Youngs, 2001).

Language learning. Lucas \& Grinberg (2008) and Clayton (2013) maintain that significant study of a second language can set a foundation for effectively connecting with and teaching MLs. Lucas and Grinberg (2008) decided that teachers with one or more years of language study in high school or college are more positive about teaching MLs, and that such teachers were more adept at identifying difficulties faced by MLs and implementing appropriate approaches for teaching language. While there is no widely accepted conclusive level of fluency or amount of time a teacher needs to spend learning a language to develop these skills, such experiences may range from rudimentary language courses taken in high school or college to multiple years of language learning experience. Such experiences seem to afford students insight into second language acquisition while helping them appreciate the social challenges faced by ML students. 
ML-related teaching. Clayton (2013) also found that the amount of time teachers spent teaching MLs was a marker of successfully educating MLs. However, she also maintained that the mere presence of MLs in a classroom is not enough; truly successful teachers also spent time reflecting on their work with these students. This construct encompasses previous-teaching experiences with MLs and reflection on these experiences.

As we later discuss, being aware of these BQs may prove useful for teacher educators who want to help preservice content teachers embrace the role of language teacher. Doing so can reveal how these factors influence prospective teachers' propensity to effectively account for MLs in their teaching and it allows instructors to identify the strengths and weaknesses of preservice teachers and respond accordingly.

\section{Research Design}

This study was conducted during a semester-long course entitled, Middle School and Secondary History Teaching Methods, at Boston College. A required course for graduate and undergraduate students planning to become secondary history teachers, one core objective is to instill a commitment to history-based pedagogical content knowledge in preservice teachers, emphasizing the process of "doing history" (Wineburg, 2001; Wineburg \& Fournier, 2004). However, as noted previously, throughout the last 10 years there has been a growing focus on accommodating the needs of MLs-a development attributed largely to the presence of a graduate assistant and faculty colleagues who helped redesign two earlier iterations of the course to make the needs of MLs more prominent. In addition, the graduate assistant, Laura Schall-Leckrone, co-taught select classes of the course over those two semesters and, along with the instructor, McQuillan, conducted two longitudinal studies on preparing prospective history teachers to work with MLs (Schall-Leckrone \& McQuillan 2012; Schall-Leckrone \& McQuillan 2013).

\section{Participants}

Our study of how preservice content teacher BQs shape their inclination and ability to support MLs in classroom instruction represents a multi-participant case study $(N=12)$ (Stake, 2006) informed by critical socio-cultural theory. From this perspective, all social practices-including one's likelihood of acknowledging a need to support the instruction of MLs and embracing opportunities to learn how to do so-are informed by some set of cultural ideals, beliefs, principles and values (Gee, 1996). To generate a cultural understanding of 'learning to teach MLs,' our study examined the BQs teacher candidates brought to the teacher education program, work they generated during class sessions, and assignments completed as course requirements-all intended to assess the relationship between participants' cultural, linguistic, pedagogical, and educational BQs and whether and how they engage in activities about and create lessons for MLs.

We utilize constructivist grounded theory to explore the relationship between novice teacher BQs, their engagement in ML-related class activities, and the curricular and pedagogical 
strategies they drew upon to support MLs in lessons they developed. Besides utilizing inductive, simultaneous data collection and analysis, we focused on Charmaz's (2017) contemporary grounded theory constructs concerning: (1) participants' multiple standpoints, roles, and realities; and (2) the position of this research in its historical and social context.

To understand how students approached our course, participants completed a presemester questionnaire focused on their BQs and a post-semester reflection on ML-related takeaways from the course that included additional background questions. (See Appendix 1.) We also collected qualitative data throughout the semester during all ML-related class activities. Further, using analytic rubrics we evaluated student performance on a range of assessments, including work completed during two classes devoted to helping pre-service teachers generate strategies to support MLs in their teaching and those developed for a culminating five-day unit plan that included a section for "Supporting All Learners" and asked students: "What will you do to ensure success from all students [including] students on individual education plans, English language learners (at a variety of English language levels), and students who may need an extended challenge (emphasis added)?" Additionally, two students participated in semistructured interviews the last week of the semester and two participated in informal interviews and an email discussion the following semester.

\section{RESULTS}

Our data reveal a strong relationship between students' diverse cultural and linguistic experiences and their ability to commit to engaging in ML-related practices in the history classroom. To varying degrees, students who possessed these BQs were better prepared to embrace their role as language teachers and tailor lessons for MLs than peers without such BQs. Of the 12 students in our course, we considered three to be exemplary embracers of the role of language teacher, seven to be strugglers who embraced the role of language teacher but were challenged in certain ML-related areas, and two who were distancers and saw the role of language teacher as rather irrelevant to their work as a content area teacher (see Figure 2). For each of these categories, we present one student who seems to best embody the nature of that particular category and allows the reader to get a rich sense for what each category looks like in practice. 
Figure 2: Embracing the Role of Language Teacher

\begin{tabular}{|l|l|}
\hline Findings & Explanation \\
\hline Embracers & $\begin{array}{l}\text { Three of twelve students were exemplary embracers, actively } \\
\text { participating in ML-related in-class activities and consistently } \\
\text { creating effective language objectives on lesson plans. }\end{array}$ \\
\hline Strugglers (1) & $\begin{array}{l}\text { Three of twelve students were embracers in terms of actively } \\
\text { participating in ML-related in-class activities, but struggled to } \\
\text { create language objectives on lesson plans. }\end{array}$ \\
\hline Strugglers (2) & $\begin{array}{l}\text { Four of twelve students were embracers in terms of creating } \\
\text { effective language objectives on lesson plans, but struggled to } \\
\text { actively participate in ML-related in-class activities. }\end{array}$ \\
\hline Distancers & $\begin{array}{l}\text { Two of twelve students distanced themselves from the role of } \\
\text { language teacher in terms of not being able to create effective } \\
\text { language objectives on lesson plans and struggling to } \\
\text { participate in ML-related in-class activities. }\end{array}$ \\
\hline
\end{tabular}

\section{Embracers}

Three students in this course, categorized as "embracers," effectively engaged with opportunities to enact the role of language teacher in all related course work, comfortably sharing teaching strategies for MLs in class and incorporating relevant LOs into their lesson planning. Examining their BQs reveals that each possessed more background indicators of successful ML teachers than their classmates, though not every one. For example, each had previous experience teaching MLs, taking an ML-related education course, and traveling to foreign countries where English was not the primary language. Two had notable language learning experiences. One student maintained that he had "limited" Spanish proficiency from taking required courses in high school, one had taken advanced placement levels of Spanish classes in high school, and the other reported becoming a fluent Spanish speaker during college. Their in-class comments and written work suggest that their BQs helped them engage with MLrelated themes when others struggled. One embracer, Colleen, embodied every BQ in our conceptual framework, offering a perspective as to how an exemplary embodiment of the BQ framework allows preservice teachers to effectively engage with ML-related materials and activities.

ML-related education. Unlike many classmates, Colleen completed her Teaching English Language Learners certificate at BC prior to taking our course, a State certification which entailed taking two courses focused on "bilingual learners" and working in a school that serves MLs. In practice, these courses served as reference points throughout the methods course, "Every time something was brought up [ML-related], I would just think, 'Oh, that is connected 
to something I learned in my other class' . . I have a larger context to think about it, or a larger background knowledge." These course experiences also influenced how she approached teaching MLs. During a group lesson planning activity, for example, she noted that she would highlight African American Vernacular English (AAVE) within the song, "Changes" by Tupac Shakur, allowing students to identify unfamiliar words, thereby hoping to empower students who use AAVE and raising awareness for its status as an English language variant, "I learned that from another class, to know that AAVE is its own language. And helping [MLs] with this definition is important for a lesson like this." Here, previous ML coursework- "I learned that from another class"-helped a preservice teacher embrace the role of language teacher in a content course, explicitly articulating the connection between her educational background and ability to account for MLs. In a similar instance, when asked why she used translanguaging in a class with MLs, she replied:

I learned about it here first [in previous BC bilingualism courses].... but didn't know the term for it or the theory behind it. For me, as someone who knows their language [referring to her MLs] . . . I can get them to where they need to get to [by translanguaging].

Additionally, this experience may have contributed to her developing asset views of her students' language use, as she reflected on their translanguaging, "I've never seen Spanglish as a negative thing, I think it shows the depth of language knowledge.... It shows higher order thinking." These experiences afforded her opportunities to formulate a theoretically-based disposition toward linguistic diversity, thereby contributing to her embracing the role of language teacher.

Cultural immersion. Colleen also had significant experience in a culture where English is not dominant, having studied in Spain for a semester during college. While she already spoke competent Spanish, this was her first time immersed in an authentic language context, a factor which shaped her teaching philosophy:

I studied abroad in Spain and had a host mom who didn't speak any English. That is the experience that has influenced me the most in my teaching...being able to empathize in a way with that position of, 'you kind of know what I'm saying, but not really because this is not your native language'... [S]o my brain was constantly working and there was never a moment of rest... [that experience] let me be cognizant of their [MLs] situation. In this account, Colleen "empathizes" with challenges ML students face, suggesting how time abroad influenced her perceptions of MLs (Clayton, 2013; Youngs \& Youngs, 2001). Also, judging by her performance in our course, it supports the assertion made by Jimenez \& Rose (2010) that "students who have lived abroad for a significant amount of time . . . are among the students best prepared to become teachers of students who are learning English" (p. 408).

Language learning. The fact that Colleen speaks Spanish fluently has also helped her in her practicum: "All of my students speak Spanish, which is helpful for me because I have been learning Spanish since third grade." This experience also shaped her teaching: "I've seen a 
variety of ways that people teach Spanish to English speakers, so it gives me that flipped perspective of a person who is trying to teach history in English to people who know Spanish." Further, these experiences help her avoid practices she considers ineffective: "When I was learning Spanish, I didn't find that kind of repetition and memorization [style of teaching] helpful at all."

ML-related teaching. Another influential BQ concerned Colleen's experience in a Sheltered English Immersion (SEI) history course at a nearby high school. As she explained, "Because of my practicum, every time I open my mouth when I'm teaching I am thinking about how I can use a word my students will understand." In a related vein, she noted that incorporating MLrelated material in a content course "is helpful, because just putting that idea in your head is important." When encountering comparable material during the semester, she could reflect on how it might play out in class; in essence, her teaching experience provided a context to assess practices she found useful, or not, for her lessons. For example, she found the "concept definition map" (Echevarria, Vogt \& Short, 2017, p. 87) to be "very helpful for MLs," but decided that a Socratic seminar would not be effective in certain circumstances. Similarly, during a group language objective activity, Colleen suggested allowing students to select words from song lyrics that "stood out," instead of simply introducing pre-selected vocabulary, the only time a student allowed pupils to identify difficult vocabulary, a common practice in ML classrooms.

Colleen's ML teaching experience also provided a foundation from which to join class discussions confidently. While discussing "bridging gaps" and teaching for social justice, for instance, she recounted a successful experience teaching Dominican students how to use a Venn diagram. With no prompting, she linked her teaching of MLs to issues of social justice, further indication of her affirming views on teaching MLs. In a lesson on creating LOs, Colleen confidently engaged in ML-related discussions, though other students struggled. After sharing her objective, the instructor asked how she would scaffold it, to which she answered, "Usually, I use guiding questions or students use Venn diagrams to compare in a more visual way" - her use of the term, "usually" suggesting her ability to draw on experience. These comments suggest Colleen could engage course content in ways classmates lacking comparable teaching experience could not.

\section{Strugglers}

We categorized seven students as "strugglers." Each embraced the role of language teacher, but struggled with certain ML-related activities. Interestingly, these students separated into two subcategories: (1) those who engaged in ML-related in-class activities, but struggled to incorporate ML-related strategies into lesson plans; and (2) those who incorporated ML-related pedagogical strategies in their lessons, but seldom made meaningful contributions during related class activities.

During the semester three students fell into the first subcategory of "strugglers." All three regularly engaged in ML-related discussions and activities, generating much in-class data 
for this study. They also had some relevant BQs-one having taken an ML-teacher education course the previous summer and completed a pre-practicum in a class with multiple MLs; another having many ML classmates and neighbors as a youth. Overall, this group willingly engaged with ML-related materials and activities in class, yet they struggled to create formal LOs when lesson planning. One struggler, Jeff, expressed frustration with incorporating linguistic scaffolds for MLs but continually displayed a commitment to accommodating MLs, as manifest in his eagerness to participate in ML-related in-class activities and ML-related discourse. His BQs reveal a mix that could explain his strong performance in certain areas and difficulty in others.

Cultural immersion. Jeff grew up in a linguistically diverse town, having Spanish-speaking friends, classmates, and neighbors. He believes his related interactions influenced how he will approach teaching MLs:

My hometown is close to $40 \%$ Puerto Rican... I was always hearing Spanish growing up. . . . so I'm not going to be taken off guard if there are students who don't speak English in my classes. . . my most vivid memory of [elementary school] was the teacher being frustrated by two girls speaking Spanish in the back.

He went on to say he would not mind students using their home language in his classes, suggesting a link between previous experiences with MLs and his inclination to engage with MLrelated activities during our course.

Language learning. Two salient language-related experiences appeared to shape how Jeff viewed teaching MLs, perhaps the most influential being his experience growing up with a learning disability. Though exempt from taking a second-language class in high school because he struggled with spelling and grammar in English, his consequent predicament led him to empathize with students challenged to grasp language-related content: "I feel like I can help ELs because I have a learning disability and know what it's like to sit in a class and have no idea what the teacher is saying." Comparably, when required to take a language class in college, this too enriched his empathy for those with linguistic challenges, "I got the whole perspective of sitting in a language class and not knowing what the teacher was talking about." This sense of empathy for MLs carried over into Jeff's classroom performance. For instance, when the instructor showed the class a PPT slide with an historical excerpt and asked, "Why is this hard for bilingual learners?" Jeff commented, "The names are difficult. Like 'Lincoln'... They might be like: 'who is that?"' A fine observation from someone with no teaching experience, and revealing instance of how this particular student consistently strove to engage in conversations concerning MLs. ML-related education and teaching. At the time of our study, Jeff had no school-based experience with MLs, but noted, "I substitute taught a few classes with MLs in them." He also had limited ML-related coursework prior to this history methods course: "I took an education class in my undergrad.... It was like, 'You read [an article about bilingual learners], so you should know it.'" He recalled no discussions or practical teaching strategies discerned from the course. The ML-focused lessons in our course were his first exposure to multilingual education. 
On two occasions, Jeff struggled to create LOs. In the first, as noted earlier, students analyzed a lesson plan from a former student, seeking to adapt the lesson for MLs. The ensuing discussion introduced students to the song, "Changes" by Tupac Shakur. In groups, an embracer explained that the song uses AAVE, and that students, MLs in particular, would need help interpreting lyrics. Jeff immediately distanced himself from this undertaking, seeing the process of adapting the lesson for MLs as a problem, not a means to enrich the activity:

I never even thought of any of the things you are talking about when I was looking at this lesson plan [referring to the use of AAVE]. I would never do this lesson with MLs. This song is way too hard.

During another class, Jeff questioned the need to create LOs at all. After outlining potential LOs in group work with classmates, Jeff summarized his thinking, "Your language objectives are not as important as the way you actually introduce language objectives in the class" characterizing lesson planning as an administrative requirement not a reflection of what "really" happens in schools, again distancing himself from the role of language teacher.

\section{Strugglers II}

Contrasted with the previous example, the four other strugglers were embracers in terms of creating effective LOs on lesson plans, but made few meaningful contributions during class activities, a development we link to their BQs. Indeed, some students may appear disinterested in ML-related activities, but have difficulty engaging the material because of a lack of immediately accessible ideas.

ML-related education and teaching. For Linda, this was her first semester taking any educationrelated course. She even mentioned being "terrified" about participating in a course where other students either had teaching experience or were graduate students: "[I]t was challenging to speak up both because I struggled to apply the experiences I've had in my own classroom experiences and volunteering a few times a week at [a local public school] to our class activities." Besides French and Spanish classes in high school, she had no significant language learning experience. In most classes, she had little to say, but clearly paid attention, internalizing many ML-related concepts and practices from class and, with time, creating excellent LOs with corresponding scaffolding on her lesson plans, a topic discussed later when we outline objectives students created for a culminating unit plan each developed.

\section{Distancers}

We categorized two students who seldom embraced the role of language teacher as "distancers," as they largely disengaged from assuming the role of language teacher, judging by their difficulty with, or avoidance of, ML-related discourse as well as their struggles to incorporate LOs into their lesson planning. Viewed through the lens of their BQs reveals that these students had few previous experiences considered indicators of exemplary ML teachers; only one had more than one BQ. Yet they did not completely disregard all ML-related activities; in fact, at times both showed encouraging signs-contributing to ML-related class discussions 
early in the semester. Nonetheless, these students likely struggled with ML-related course features, at least partly, because they lacked BQs that would otherwise motivate them to engage with materials and opportunities in meaningful ways.

ML-related education and teaching. One of the more salient comments from this group came during a discussion on LOs during the final class. The speaker, Carl, was in a full-practicum with no MLs in his courses, nor in any previous classrooms in which he taught. When asked which LOs he would use in his unit plan, he replied, “We don't do language objectives at my school. I feel like teaching MLs and language objectives is something that just gets swept under the rug [in his school]." Carl also expressed skepticism about enacting effective LOs as well as teaching MLs:

I don't think it's something you can just learn quickly in a class. You need to be super qualified to teach those students. There is no way I am qualified to teach them. I don't even speak a lick of Spanish. So, when we talk about doing LOs and we write them, it's like I am in no way qualified to actually use them. . . It is totally different in a real class and just making them on a lesson plan.

In his remarks, Carl connected his lack of BQs-no foreign language fluency, no experience teaching MLs - with his inability to embrace the role of language teacher. Even creating LOs in a lesson plan would in no way prepare him to enact those objectives in an actual lesson. This sense that LOs were not a requirement in an authentic school setting, validated by his full-time teaching position, likely contributed to distancing himself from ML-related coursework, as it seemed inapplicable to his current, real world teaching situation.

\section{Unit Plan Language Objectives}

The culminating assignment for this course required students to create a five-day unit plan on some historical topic. Offering another perspective on the ability and inclination of students to create LOs to support MLs we present sample language objectives students from all three groups created for their unit plans. The lesson plan format (generated by the Boston College Practicum Office for all content methods courses) asks students to "Choose 3 examples of support from the list [of possible language supports] and explain in detail the differentiation [enacted for your lesson]." For each student we selected sample LOs that represented the most robust "examples of support" each created.

\section{Embracers}

The ML-supportive LOs presented by the embracers each include at least three different manifestations of linguistic support, all aligned with lesson objectives. Specific strategies entail "doing history" or systemic functional linguistics (Daniello, et al., 2014; Wineburg, 1991), the use of graphic organizers (Hall \& Strangman, n.d.), creating word banks, using a concept definition map (Echevarria, Vogt \& Short, 2017, p. 87), employing artful thinking routines (Tishman \& Palmer, 2006), or embracing a topic linked to issues of 
social justice as motivation for engagement (Teemant \& Hausman, 2013). Notably, individual language objective examples we include entail at least three means of supporting MLs learning.

Morgan's lesson, a study of early twentieth century feminism that critically examined the treatment of "flappers" in U.S. society, offered students varied ways to participate in class discussion:

I will put sentence stems on the board to offer ways students can participate if they are nervous. . . . Discussion questions will be collected, so if a student feels nervous to participate, I still know they engaged with the video. . . .

Focused on an individual student, Colleen customized her instruction for that student's needs:

I have one student who struggles to write due to a disability so after I instruct students on how to complete the activity. ... I will circulate throughout the room but spend time working with her specifically so she can verbally answer the questions. ... .

Charles drew on the practices of systemic functional linguistics to "do history", integrating that with aspects of artful thinking:

Students will explain that African Americans were protesting the systemic oppression that stemmed from Jim Crow Laws and will 'do history' . . . by completing a beginning-middle-end artful thinking activity relating to select images from the movement.

To create effective accommodation strategies for MLS the LO supports implemented by embracers integrated varied scaffolding strategies, all aligned with the overarching objectives.

\section{Strugglers}

This group included students committed to enriching the learning of MLs by drawing on LOs during in-class activities but were ineffective in doing so for the unit plan. They have valuable insights to offer and willingly share them, but need time and experience to enrich their understanding of ML-related pedagogies. Jeff, for instance, included the following in his unit plan on the Separation of Powers in the Federal Government: "Students will be provided guided notes and graphic organizers to fill out during the lesson and use as a reference." The lesson included no examples of guided notes and the graphic organizer used for all five lessons had the same image of the three branches of government with arrows suggesting how power might be divided among them. Students were told, "Over the course of the unit, label the arrows with the appropriate checks and balances." Frank, who focused his unit on World War II, sought to get students to "write and verbalize their thoughts when looking at images from Pearl Harbor" by asking students to "write down their $10 \times 2$," an artful thinking routine in which students record their first ten reactions to a photo, reflect on their choices, and then reflect a second 
time with ten more reactions. The associated objective seemed vague, noting that students should "be able to verbally share." In a unit on causes of the Civil War, Matt asked students to select five terms from a "List of Concepts" and complete concept definition maps for each. These graphic organizers offer a rich way to understand important vocabulary but connection to any LOs were unclear.

Overall, their strategies offered limited scaffolding toward any specific LOs. Jeff's highlighted the fact that the three branches of government possess differing powers but asked students to do no higher order thinking nor synthesize or evaluate any data sources beyond placing them in the correct structural context. Frank's $10 \times 2$ strategy asked students to describe powerful images from Pearl Harbor but offered no opportunity to reflect upon their decisions beyond "writing and verbalizing their thoughts." Matt's strategy helped students grasp important vocabulary terms that were central to work done in his unit, with little sense for how they might be used in the lesson.

A second group of four strugglers were committed to integrating LOs into their unit plans but offered few meaningful contributions to related class activities. Sean's unit plan offered MLs the following supports to develop notetaking skills: "Writing and drawing notes; modeling the note taking process; and individual check-ins during note taking," all of which seem as though they would enrich students' note taking skills. Gina's most compelling strategy blended two relevant practices, sentence stems and graphic organizers: "ML students will receive a sentence stem and/or graphic organizer depending on their proficiency for understanding the reading," two strategies with the potential to scaffold MLs' learning.

Linda integrated a graphic organizer with an artful thinking routine to "do history": "Students will complete a Think/Puzzle/Explore graphic organizer including a copy of the image (the original historical source), which is a helpful tool for 'doing history' [in a lesson on 'Bleeding Kansas.']." The final student in this group, Sam, blended a translanguaging strategy with a word bank and graphic organizer to help students connect the Atlantic Slave Trade with Columbus' arrival in the New World:

support [students'] access to content by providing . . . graphic organizers, complementary vocabulary, [and] alternative definitions and concepts in [students'] native language, utilizing their native language to develop their literacy skills.

These examples are strong; however, in class activities these students offered few ideas when conceptualizing how history teachers might help MLs enrich their language proficiency.

\section{Distancers}

During the semester, these students seldom engaged in ML-related class discussions or exercises. Their efforts to create "three examples of support" for MLs with their unit plans were limited. Carl's most extensive enactment of LOs included the following:

- Sentence Starters for Comprehension Questions 
- Vocabulary Graphic Organizers

- Individual prints for Paul Revere's engraving

Though potentially rich ideas, his description included no more information, no examples of sentence starters nor relevant graphic organizers. A second distancer, George, had LOs for one lesson over five days. It allowed students choice of the form each lesson resource might take:

Students will have hard copies of the primary sources, as well as having the sources projected on the large screen in the front of their class and have an opportunity to access the sources via their cell phones. Students may choose which method works best.

Overall, these examples offer three insights: First, the embracers, as during the semester, created rich and relevant LOs. The strugglers, building on what they had done during the semester and given the time and opportunity to create LOs, also did a fine job. And third, the distancers continued to show little interest in creating LOs for their lessons.

\section{DISCUSSION}

\section{Educational Significance}

For us, the most notable finding from this study is that over half our class fell into either the strugglers or distancers categories, as students' words and actions, to varying degrees, disengaged them from responsibility for helping MLs grasp the language of historical analysis, not unlike what occurred in two previous studies of this course where students "had difficulty actually creating language objectives for the unit plan assignment" (Schall-Leckrone \& McQuillan, 2013, p. 93). By disaggregating students into three conceptual groupingsembracers, strugglers, and distancers-various pedagogical and curricular implications become apparent. To begin, with the strugglers in mind, instructors need to recognize that difficulties students have with ML-related concepts and practices may not reflect inadequate effort but rather a lack of relevant experiences to draw upon when asked to contribute during class or when crafting LOs for a lesson plan. As students typically have differencing structures/arrangements to their programs of study, including ML-related coursework, they will likely bring diverse experiences and understandings to your class-including whether they have taught MLs or taken a course aimed at enriching their ability to teach MLs. In your teaching, instructors may want to encourage students who have taught MLs or taken ML-related coursework to introduce ideas from other courses or their teaching into your class. Ask them to go beyond your syllabus. For less experienced students, offer scaffolds such as think-pair-shares or concept definition maps, that will enable them to complete relatively straightforward MLrelated practices that can still generate rich understandings and serve as a foundation for later growth. Know who these students are and be prepared to support them.

In another manifestation of how differing programs of study may impact student performance, instructors should keep in mind that in group activities students with more significant BQs, such as having already taken coursework linked to teaching MLs or actually having taught ML students. With such background experiences to draw upon, these students 
may dominate discussion and restrict participation by classmates, especially if those students question the very relevance of attending to the needs of MLs. When groups "report out," you may actually only hear the ideas of stronger students. In our course, when students developed LOs in group work, only one student from each group presented the LOs to class, all of which were fine. In retrospect, only some students, typically stronger students, spoke about creating LOs. Allowing all students to discuss teaching LOs would help instructors better understand which students grasp this critical skill and identify potential strugglers early on.

To address such BQ-related concerns, schools of education could strive to make the teacher education system more "coherent", that is, ensure students receive similar or at least complementary messages across teacher education course work (McQuillan, Welch, \& Barnatt, 2012). As presently constituted, the teacher education program requires students to take two courses on pedagogical and contextual issues linked to working with MLs. However, there is no requirement as to when courses are taken. ML-related coursework can occur before methods courses, after methods courses, or both before and after methods coursework, a development we suspect is common beyond Boston College. As a consequence, when students take content methods courses, they may have had two semesters of ML-related course work or none, and as we aimed to convey, this factor can shape how students respond when addressing the needs of MLs.

With this issue in mind, faculty could administer an introductory survey in each relevant course-those focused on working with MLs or content area coursework-to assess students' teaching-related skills, including their facility with supporting MLs language growth. This survey, which could be collectively designed by teacher education faculty, might identify a check list of practices and allow students to signal where they feel confident in their pedagogical skills and where they need additional support. Faculty could tailor instruction to students' specific BQs. Students who already have strategies for teaching vocabulary, could move on to more challenging practices, such as 'doing history' (Wineburg, 1991) or artful thinking routines (Tishman \& Palmer, 2006). Those with fewer BQs may need additional supports. An introductory survey could target their needs.

Moreover, helping students understand how their BQs shape their instructional practices would offer students insight into the nature of how teaching practices emerge and evolve, in and of itself a powerful lesson. As became apparent in reviewing students' unit plans, we never pushed them to go beyond their existing understanding of LOs. We exposed them to varied instructional practices and related theoretical foundations but never required, nor even strongly encouraged, them to develop facilities across a range of strategies. Most ML-related practices were acceptable, though an overreliance on certain practices might inhibit our students' growth. The impact of this oversight was evident with their unit plans as students drew on a limited repertoire of strategies, with every student using some LOs multiple times, suggesting that all three groups-embracer, strugglers, and distancers-had limited repertoires to draw upon. Certainly, redundancy can reinforce central ideas and practices, but encouraging 
students to explore new forms of LOs can enrich their long-term teaching skills. A quick survey of students at a semester's outset could help faculty identify students' skills and shortcomings. Having faculty collectively design the survey could enhance faculty understanding and ability to modify what each other do in their courses regarding LOs for MLs, ideally enhancing the likelihood students receive a well-rounded understanding of strategies for working with MLs.

Often, pedagogical and curricular innovations initially target specific student groups and needs, a classic example being that Universal Design for Learning (Rose \& Meyer, 2006) was conceptualized initially to aid special needs students. Now, it is understood as a means to enrich all students' learning. We believe the same holds true with creating LOs for MLs. What history lesson doesn't involve LOs? And what teachers and students, regardless of their linguistic backgrounds, would not benefit from having relevant LOs integrated into lessons? As our study reveals, some students need to be convinced of the relevance of creating LOs for their lessons. As seems evident in the culminating unit plans, when teachers do integrate explicit LOs into every lesson, it clarifies the nature of those LOs as well as the means by which they will be assessed, thereby potentially benefiting all students, regardless of linguistic background. In this sense, LOs become a means to enact social justice, a common priority for teacher education programs nationwide.

\section{CONCLUSION}

Given this study, we maintain that content teacher candidates' background has a substantial effect on their ability to enact practices that will enrich the learning of MLs in history methods courses and to embrace the role of language teacher. We intend this study to contribute to understanding the currently uncertain relationship between teachers' backgrounds and effective and inclusive teaching techniques, in terms of accounting for MLs in the content classroom. In future iterations of this course, it would seem logical to allow time for preservice teachers to read this manuscript and reflect on their own BQs and the impact those experiences might have on their course performance. Ideally, understanding this relationship could facilitate preservice teacher engagement with ML-related activities and thereby lead them to internalize ML-related pedagogical techniques and understandings while offering insight into their personal process of professional growth. Potentially, drawing on these insights will allow our students to embrace the role of language teacher, which can empower them to develop and implement pedagogical strategies for working with MLs in an authentic classroom setting.

One final point is crucial to our analysis: We needed to listen more to students. We made ML-related pedagogical practices and LOs central to our course. Yet when trying to create relevant LOs some students were confused. Further, at times a sense of disinterest regarding the education of MLs was palpable but never addressed. Given these developments and outcomes from the previous two studies of this course, the need for respecting students' point of view and opportunities for them to stop and reflect now seem quite evident. We should have engaged students in a collective analysis of our course, with a focus on concerns linked to 
teaching MLs. We should have talked with those who felt confident using LOs and explicitly drawn on their experience to enrich the work other students produced. Beyond its pedagogical value, this would have been a wonderful opportunity to model respect and inquiry in the classroom for all students.

\section{REFERENCES}

American Council on Education. www.acenet.edu

Brisk, M. E., Homza, A., \& Smith, J. (2014). Preparation to practice: What matters in supporting linguistically responsive mainstream teachers. In Research on preparing preservice teachers to work effectively with emergent bilinguals (pp. 167-199). Emerald Group Publishing Limited.

Charmaz, K. (2017). Constructivist grounded theory. The Journal of Positive Psychology, 12(3), 299-300.

Clayton, C. (2013). Exemplary teachers of English Language Learners: A knowledge base. Journal of Research in Education, 23(2), 35-64.

Cochran-Smith, M., \& Fries, K. (2005). Researching teacher education in changing times: Politics and paradigms. Studying teacher education: The report of the AERA panel on research and teacher education, 69-109.

Daniello, F., Turgut, G., \& Brisk, M. E. (2014). Applying systemic functional linguistics to build educators' knowledge of academic English for the teaching of writing. In Englishes in multilingual contexts (pp. 183-203). Springer, Dordrecht.

Darling-Hammond, L., \& Bransford, J. (Eds.). (2007). Preparing teachers for a changing world: What teachers should learn and be able to do. John Wiley \& Sons.

De Jong, E. J., \& Harper, C. A. (2005). Preparing mainstream teachers for English-language learners: Is being a good teacher good enough?. Teacher Education Quarterly, 32(2), 101-124.

DelliCarpini, M. e., \& Alonso, O. B. (2014). Teacher education that works: Preparing secondarylevel math and science teachers for success with english language learners through content-based instruction. Global Education Review, 1(4), 155-178.

DiCerbo, P. A., Anstrom, K. A., Baker, L. L., \& Rivera, C. (2014). A review of the literature on teaching academic English to English language learners. Review of Educational Research, 84(3), 446-482.

Echevarria, J., Vogt, M., \& Short, D. (2000). Making content comprehensible for elementary English learners. The SIOP Model. Boston, MA: Allyn \& Bacon.

Echevarria, J., Vogt, M., \& Short, D. (2017). Making content comprehensible for elementary English learners. The SIOP Model. Boston, MA: Pearson.

Fang, Z., \& Schleppegrell, M. J. (2008). Reading in secondary content areas: A language-based pedagogy. Ann Arbor: University of Michigan Press. 
Hall, T. E., Meyer, A., \& Rose, D. H. (Eds.). (2012). Universal design for learning in the classroom: Practical applications. Guilford Press.

Hall, T., \& Strangman, N. (2002). Graphic organizers. National Center on Accessing the General Curriculum, 1-8.

Hopkins, M., Gluckman, M. \& Vahdani, T. (2019). Emergent change: a network analysis of the elementary teachers learning about English learner instruction. American educational research journal, volume 56, Number six, pp. 2295-2332.

Hynd, C. (1999). Teaching students to think critically using multiple texts in history. Journal of Adolescent and Adult Literacy, 42(6), 428-4361

Jimenez, R. T., \& Rose, B. C. (2010). Knowing how to know: Building meaningful relationships through instruction that meets the needs of students learning English. Journal of Teacher Education, 61(5), 403-412.

Lesh, B. (2011). "Why Won't You Just Tell Us the Answer?": Teaching Historical thinking in grades 7 -12. New York: Stenhouse Publishers, Chapter 3, "Text, Subtext, and Context."

Lucas, T., \& Grinberg, J. (2008). Responding to the linguistic reality of mainstream classrooms: Preparing all teachers to teach English language learners. Handbook of research on teacher education: Enduring questions in changing contexts, 3, 606-636.

Márquez-López, T. (2005). California's standards movement: How English learners have been left out of the equation for success. Latino education: An agenda for community action research, 205-230.

Martin-Beltran, M., \& Peercy, M. M. (2014). Collaboration to teach English language learners: Opportunities for shared teacher learning. Teachers and Teaching, 20(6), 721-7373.

Master, B., Loeb, S., Whitney, C., \& Wyckoff, J. (2016). Different skills? Identifying differentially effective teachers of english language learners. The Elementary School Journal, 117(2), 261-284.

McQuillan, P. J., Welch, M. J., \& Barnatt, J. (2012). In search of coherence: 'Inquiring' at multiple levels of a teacher education system. Educational Action Research, 20(4), 535551.

Rose, D. H., \& Meyer, A. (2006). A practical reader in universal design for learning. Harvard Education Press. 8 Story Street First Floor, Cambridge, MA 02138.

Schall-Leckrone, L. \& McQuillan, P.J. (2013). Collaboration within a Teacher Education Program: Preparing History Teachers to Teach English Learners. In J. Nagle (Ed.) Creating Collaborative Learning Communities to Improve English Learner Instruction: College Faculty, School Teachers, and Pre-service Teachers Learning Together in the 21st Century. Charlotte, NC: Information Age Publishing, Inc. Schall-Leckrone, L. \& McQuillan, P.J. (2012). Preparing History Teachers to Work with English Learners through a Focus on the Academic Language of Historical Analysis. Journal of English for Academic Purposes, 11, 246-266. 
Short, D. (1994). Expanding middle school horizons: Integrating language, culture, and social studies. TESOL Quarterly, 28(3), 581-608.

Sleeter, C. E. (2008). Preparing White teachers for diverse students. In M. Cochran-Smith, S. Feiman-Nemser, \& J. McIntyre (Eds.), Handbook of research on teacher education: Enduring issues in changing contexts (3rd ed., pp. 559-582). New York, NY: Routledge.

Teemant, A., \& Hausman, C. S. (2013). The Relationship of Teacher Use of Critical Sociocultural Practices with Student Achievement. Critical Education, 4(4).

Tishman, S., \& Palmer, P. (2006). Artful thinking. Stronger thinking and learning through the power of art. Cambridge MA: Harvard Graduate School of Education.

Vázquez-Montilla, e., Just, M., \& Triscari, r. (2014). Teachers' dispositions and beliefs about cultural and linguistic diversity. Universal Journal of Educational Research, 2(8), 577587.

Viesca K. M., \& Teemant, A. (2019). Preparing Content Teachers to Work with Multilingual Students. The Handbook of TESOL in K-12, 371-385.

Wineburg, S. S. (1991). On the reading of historical texts: notes on the breach between school and academy. American Educational Research Journal, 28(3): 495-519.

Zwiers, J. (2006). Integrating academic language, thinking, and content: Learning scaffolds for non-native speakers in the middle grades. Journal of English for Academic Purposes, 5(4), 317-332. 
APPENDIX 1

Background Questions (Beginning of Semester)

\section{General Questions}

1. What is your major?

2. Where are you from? (Country / City / Town)

3. What are the names of the 2 previous educational institutions that you attended?

a.

b.

\section{Teaching Background (general)}

1. Briefly describe your teaching experience. (Position? Institution? Course? Age of student? How long? Etc.)

2. What do you consider your strong points as a teacher?

3. Which areas do you feel that you need to improve upon as a teacher?

\section{Teaching Background (bilingual learners)}

1. Briefly describe your experience teaching bilingual learners (Which school(s)? How many students? Where were they from? Etc.)

2. Reflecting on your experience with bilingual learners, do you have any memories of specific difficulties you faced? Or ways you altered your lessons because of these students?

\section{Linguistic Background}

1. Do you know any other languages? Please describe your language learning experience and level of ability for each language. (Even if it is just a few phrases in a specific language, please make a note of it.)

\section{Cultural Background \& Travel Experience}

1. What is your race/ethnicity?

2. Would you say that you have a culturally diverse background? (i.e. how diverse was the place you grew up? the schools you attended? the jobs you have had? Etc.)

3. Have you ever been abroad? (Where? How long? Why?) 


\section{Course Reflection Questions (End of semester)}

\section{General Information:}

1. Prior to this course, did you take any course(s) where the curriculum focused on teaching bilingual learners? Which course(s)? What are some examples of topics you covered in the course(s)?

2. Have you had any additional teaching experience since the beginning of this semester (since August 2019)? If so, please describe in some detail (position, course, age of students, duties, etc.)

3. Which type of teaching position do you hope to get in the future?

\section{Please answer the following questions about the class}

1. Do you feel that you became a better teacher this semester? Please describe. (i.e. which specific areas or skills)

2. Do you feel that you are more prepared to teach bilingual learners? Please describe.

3. Which activities, readings, or assignments do you feel will be the most helpful for teaching bilingual learners in the future?

4. Do you anticipate any difficulties teaching bilingual learners in your future teaching positions? Please be specific.

5. Are there any difficulties with teaching bilingual learners that you feel you will not encounter in your future teaching position(s) because of something you learned in this class? Please be specific.

6. Do you have any questions regarding bilingual learners that went unanswered this semester?

\section{Further Reflection: Teacher Identity and Teaching Bilingual Learners}

1. How do you feel your personal background (i.e. education, hometown, work experience, etc.) influenced how you accounted for bilingual learners during this class? (i.e. during assignments or class activities) Please give an example.

2. Do you feel that your identity (in terms of race, ethnicity, language, socioeconomic status, etc.) influenced how you accounted for bilingual learners during this class? (i.e. during assignments or class activities) Please give an example.

3. Do you feel that your previous language learning experience influenced how you accounted for bilingual learners during the course? How so?

4. Do you feel that your previous experience(s) abroad or in a different culture(s) influenced how you accounted for bilingual learners during the course? How so? 